Special issue of the International Conference on Computational and Experimental Science and Engineering (ICCESEN 2014)

\title{
Evaluation of Antioxidant Activity, Phytochemicals and ESR Analysis of Lavandula Stoechas
}

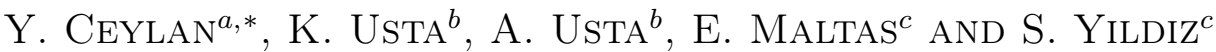 \\ ${ }^{a}$ Selcuk University, Faculty of Science, Department of Physics, Konya, Turkey \\ ${ }^{b}$ Alanya Alaaddin Keykubat University, Alanya Engineering Faculty, Alanya, Antalya, Turkey \\ ${ }^{c}$ Selcuk University, Faculty of Science, Department of Chemistry, Konya, Turkey
}

\begin{abstract}
The antioxidant activity of phytochemicals and of the methanolic extract of Lavandula stoechas was evaluated by $\beta$-carotene-linoleate bleaching, DPPH radical scavenging, ferric reducing/antioxidant power (FRAP). The obtained results were compared with antioxidant activities of synthetic antioxidants, such as BHT and BHA. The highest antioxidant activity of the extract was observed by DPPH radical scavenging assay, which was $84.45 \pm 5.1 \%$ at $1 \mathrm{mg} \mathrm{ml}^{-1}$. Rutin, rosmarinic acid, and caffeic acid were main phenolics in the extract. The total phenolic content of the methanolic extract of Lavandula stoechas was found to be $105.5 \pm 2.7 \mathrm{mg}$ gallic acid equivalent (GAE). Electron spin resonance (ESR) measurements were also performed on the samples. Free radicals were determined by ESR method. $g$ value was found to be 2.0034 for the Lavandula stoechas; 2.0052 for quercetin.
\end{abstract}

DOI: 10.12693/APhysPolA.128.B-483

PACS: 87.66.Uv, 36.20.Kd, 39.30.+w, 33.35.+r

\section{Introduction}

Antioxidants such as vitamins $\mathrm{E}$ and $\mathrm{C}$, selenium, and carotenoids decrease or inhibit the occurrence of the free radicals [1-3]. Synthetic antioxidants such as butylated hydroxyanisole (BHA), butylated hydroxytoluene (BHT), and tert-butyl hydroquinone have been used in food industry since 1940s. Recently, their safety has been questioned [4]. Therefore, attention of many research groups and institutions has been focused on usage of natural antioxidants. Lately, large efforts have been made to develop effective antioxidants for the purpose of inhibition of harmful effects of free radicals, released from the damaged human tissues by several biochemical pathways, such as lipid peroxidation on cell membrane and nucleotide mutation in DNA [5]. Antioxidant properties of the plants are attributed to their chemical composition which is composed of phytochemicals such as phenolic acids, flavonoids (quercetin, etc.). Polyphenolics are known as secondary metabolites of plants. Secondary metabolites are mainly used in food, pharmaceutical, chemical, cosmetic industries, and agriculture [6].

In this study, antioxidant activitiy of Lavandula stoechas grown in Southern Turkey was evaluated by $\mathrm{DPPH}, \mathrm{FRAP}$, and $\beta$-carotene bleaching. Several phenolic acids and flavonoids of methanolic extract of $\mathrm{La}$ vandula stoechas were also analysed by high performance liquid chromatography (HPLC). The ESR technique was also used to analyse mechanism of free radical scavenging.

*corresponding author; e-mail: yceylan@selcuk.edu.tr

\section{Materials and methods}

\subsection{Plant}

Lavandula stoechas was collected from Antalya, a city in Southern Turkey in July 2008. Leaves of the Lavandula stoechas were identified by Suleyman Gokturk and a voucher specimen was deposited in Department of Biology, Akdeniz University (Antalya, Turkey). Leaves were dried under the sun and turned into powder.

\subsection{Chemicals}

$\beta$-carotene, linoleic acid, butylated hydroxytoluene (BHT), 2,2-diphenyl-2-picrylhydrazyl (DPPH), polioxyethylenesorbitan monolaurat (Tween 20), gallic acid, butylated hydroxyanisol (BHA), and potassium ferricyanide were purchased from Sigma-Aldrich; FolinCiocalteu reagent, sodium bicarbonate, sodium acetate, ferric chloride $\left(\mathrm{FeCl}_{3} \cdot 6 \mathrm{H}_{2} \mathrm{O}\right)$, chloroform and methanol were purchased from Merck. Double-distilled water was used for all experiments.

\subsection{Preparation of extract}

Leaves of Lavandula stoechas were turned into powder by grinding. $20 \mathrm{~g}$ of the powder was extracted with $500 \mathrm{ml}$ of methanol at $35^{\circ} \mathrm{C}$ using a magnetic stirrer for $6 \mathrm{~h}$. The mixture was filtered through filter paper. Then the extract solution $(10 \mathrm{ml})$ was evaporated under vacuum and was dried at $-50^{\circ} \mathrm{C}$ in a lyophiliser (yield, $7 \% \mathrm{w} / \mathrm{w}$ ). Obtained extract was kept for the antioxidant assays.

\section{4. $\beta$-carotene-linoleate bleaching assay}

The antioxidant activity of the extract was studied using the $\beta$-carotene-linoleate bleaching method described by Velioglu et al. [7]. BHT and BHA were used as the 
standards. $0.2 \mathrm{ml}$ of tween $20,0.2 \mathrm{mg}$ of $\beta$-carotene in $1 \mathrm{ml}$ chloroform, and $0.02 \mathrm{ml}$ of linoleic acid were poured into a flask. This mixture was added to $2 \mathrm{mg} \mathrm{ml}^{-1}$ of methanolic extract, and then keep under vacuum at room temperature. A rotary evaporator was used to remove chloroform. After the evaporation, $50 \mathrm{ml}$ of double-distilled water was added to the mixture and then this mixture was shaken vigorously to obtain an emulsion. An aliquot of emulsion was placed in a water bath at $50^{\circ} \mathrm{C}$. The absorbance was recorded at $470 \mathrm{~nm}$, in 15 minutes intervals for $2 \mathrm{~h}$ using a Shimadzu 1700 UV spectrophotometer (Shimadzu Corporation, Kyoto, Japan) with double beam. Antioxidant activity of the extract was compared with those of BHT and BHA, according to degradation rate. Degradation rate $(D R)$ was calculated from Eq. 1 described by AlSaikhan et al. [8]

$$
D R=\ln (a / b),
$$

where $a$ is absorbance at initial time, $b$ is absorbance at 120 minutes. Antioxidant activity $(A A)$ was calculated using Eq. 2,

$$
A A=\left[\left(D R_{\text {control }}-D R_{\text {sample }}\right) / D R_{\text {control }}\right] \times 100,
$$

where $D R_{\text {control }}$ is the degradation rate of the control, $D R_{\text {sample }}$ is the degradation rate of the extract or standard antioxidant.

\subsection{DPPH radical scavenging assay}

The scavenging activity was estimated using the method described by Sanchez-Moreno [9]. $0.5 \mathrm{ml}$ of various concentrations of the extracts $\left(0.1-0.5 \mathrm{mg} \mathrm{ml}^{-1}\right)$ in methanol were added to $3 \mathrm{ml}$ of DPPH (2,2-diphenyl-2picrylhydrazyl) solution (0.004\%) in methanol. After the mixture was incubated in darkness at room temperature for 30 minutes, the absorbance was recorded at $517 \mathrm{~nm}$ by UV spectrophotometer (Shimadzu Corporation, Kyoto, Japan). Inhibition of the free radical by DPPH $(I)$ was calculated from the Eq. 3 described by Kartal et al. [2]

$$
I=\left[\left(A_{\text {blank }}-A_{\text {sample }}\right) / A_{\text {blank }}\right] \times 100,
$$

where $A_{\text {blank }}$ is absorbance of the blank (containing all reagents except the extract or standard), and $A_{\text {sample }}$ is absorbance of the extract or standard.

Value of $I C_{50}$ was determined from the plot of scavenging activity, drawn according to the concentration of the extract, which is defined as the total antioxidant activity necessary to decrease by $50 \%$ the initial DPPH radical concentration. The experiments were carried out in triplicate. Butylated hydroxytoluene (BHT) and butylated hydroxyanisol (BHA) were used as standard antioxidants.

\subsection{Ferric reducing/antioxidant power (FRAP) assay}

Ferric-reducing antioxidant power of the extract was investigated by the method developed by Oyaizu [10]. Different amounts of the extracts $\left(0.025-0.4 \mathrm{mg} \mathrm{ml}^{-1}\right.$ ) in methanol were mixed with $2.5 \mathrm{ml}$ of phosphate buffer $(0.2 \mathrm{M}, \mathrm{pH} 6.6)$ and $2.5 \mathrm{ml}$ of potassium ferricyanide $(1 \%)\left[\mathrm{K}_{3} \mathrm{Fe}(\mathrm{CN})_{6}\right]$. The mixture was incubated at $50{ }^{\circ} \mathrm{C}$ for 20 minutes. The mixture was added to aliquot of trichloroacetic acid (10\%). Then, this mixture was centrifuged for 10 minutes. The obtained upper layer $(2.5 \mathrm{ml})$ was transferred to another tube with $5 \mathrm{ml}$ of distilled water and then $1 \mathrm{ml}$ of ferric chloride $(0.1 \%)$ was added to the obtained mixture. The absorbance was measured at $700 \mathrm{~nm}$. The tests were run in triplicate.

\subsection{Total phenolic content}

Total phenolic content of the extract was determined using the Folin-Ciocalteu's phenol reagent by the method described by Singleton and Rossi [11]. $1 \mathrm{ml}$ of sample with various concentrations ranging from 1.0 to $0.1 \mathrm{mg} \mathrm{ml}^{-1}$ was dissolved in $1.5 \mathrm{ml}$ of distilled water, $2.5 \mathrm{ml}$ of $10 \%$ Folin-Ciocalteu's phenol reagent, and $7.5 \mathrm{ml}$ of $\mathrm{Na}_{2} \mathrm{CO}_{3}(20 \%)$. The final mixture was shaken and incubated in the dark for $2 \mathrm{~h}$. The absorbance of the mixture was measured at $750 \mathrm{~nm}$. The results were expressed as gallic acid equivalent $\left(\mu \mathrm{g}\right.$ GAE g ${ }^{-1}$ dry weight of extract). All tests were carried out in triplicate.

\section{8. $H P L C$ analysis}

A Shimadzu 1100 series HPLC equipped with a SIL10ADVP autosampler and LC-10ADVP pump system, diode array detector (DAD) and an Inertsil Agilent Eclipse XDB column (Agilent Technologies, Palo Alto, $\mathrm{CA}, \mathrm{USA})(240 \mathrm{~mm} \times 4.60 \mathrm{~mm}, 5 \mu \mathrm{m}$ particle size $)$ were used to analyse several phenolic acids and flavonoid in the extracts. The mobile phase consisted of (A), $100 \%$ methanol; (B), 3\% (v/v) aqueous acetic acid. Secondary metabolites were separated with a linear gradient from $5 \%$ to $66.5 \%$ solvent A over 75 minutes at $0.8 \mathrm{ml} \mathrm{min}^{-1}$, as described by Maltas et al. [12]. The detection was done at the wavelength of $278 \mathrm{~nm}$. Injection volume was $20 \mu \mathrm{l}$ of standards and extract. After elution was completed, the column was returned to the initial conditions and equilibrated for 15 minutes. Amounts of the antioxidant compounds, which were gallic acid, catechin, caffeic acid, epicatechin, p-coumaric acid, ferulic acid, vitexin, rutin, naringin, hesperidin, apigenin, rosmarinic acid, eriodictyol, quercetin, naringenin, luteolin, apigenin and carvacrol, were calculated on the basis of the calibration curve for each of them.

\subsection{ESR measurement}

The measurements were performed using an ESR spectrometer (X-Band Bruker EMX 081, Rheinstetten, Germany) in Saraykoy Laboratory of TAEK (Turkish Atomic Energy Authority). The measurements were set as follows: the microwave power was $2 \mathrm{~mW}$, the modulation frequency was $100 \mathrm{kHz}$, and modulation amplitude was $0.5 \mathrm{G}$.

\subsection{Statistical analysis}

The statistical analysis was carried out using OriginPro 7.5 software and one way analysis of variance (ANOVA) method. Obtained results were compared using Tukey test. 


\section{Results and discussion}

\subsection{Antioxidant activity}

\subsubsection{DPPH radical scavenging assay}

The proton radical scavenging is known to be one of the various mechanisms in measurement of antioxidant activity. The scavenging effect of antioxidants on $\mathrm{DPPH}$ radical has been investigated [12-13] by many researchers. In this study, DPPH showed a maximum absorption at $517 \mathrm{~nm}$. When the methanolic extract of Lavandula stoechas was added to DPPH solution, purple colour of the solution rapidly faded. The inhibition percentage of methanolic extract of Lavandula stoechas, ranging from 0.05 to $0.5 \mathrm{mg} \mathrm{ml}^{-1}$, is shown in Fig. 1 .

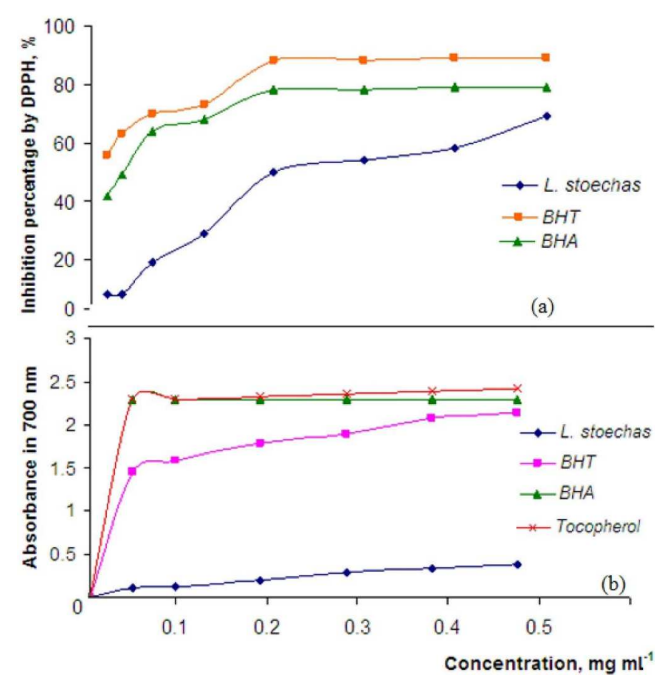

Fig. 1. Inhibition ratio (\%) against increasing Lavandula stoechas extract concentration in DPPH assay (a) and absorbance changes against increasing concentration of the methanolic extract of Lavandula stoechas in FRAP assay (b).

Synthetic antioxidant standards, BHA and BHT, were applied to the DPPH method in the same concentration range. It was found that inhibition percentage of DPPH by Lavandula stoechas extract was $69.31 \pm 1.24 \%$ at extract concentration of $0.5 \mathrm{mg} / \mathrm{ml}$; inhibition percentages of BHT and BHA were $89.16 \pm 1.83 \%$ and $80.01 \pm 1.78 \%$, respectively (Table I). Extract concentration providing $50 \%$ inhibition $\left(I C_{50}\right)$ of Lavandula stoechas is given in Table I.

The obtained data show that the methanolic extract of Lavandula stoechas can be used to reduce the stable DPPH radical with $I C_{50}$ values of $0.300 \pm 0.010 \mathrm{mg} \mathrm{ml}^{-1}$. $I C_{50}$ values of BHT and BHA were $0.020 \pm 0.001 \mathrm{mg} \mathrm{ml}^{-1}$ and $0.035 \pm 0.007 \mathrm{mg} \mathrm{ml}^{-1}$, respectively. Phenolic acids and flavonoids of Lavandula stoechas, such as rutin and caffeic acid have been reported as the compounds responsible for the antioxidant activity [14]. As a matter of fact, all phenolic materials in the extract have been known to contribute to antioxidant activity of the methanolic extract of Lavandula stoechas.
TABLE I

DPPH scavenging activity, antioxidant activity by $\beta$-carotene-linoleic acid system and $I_{50}$ values of the methanolic extract of Lavandula stoechas and standards.

\begin{tabular}{c|c|c|c}
\hline \hline Extract & $\begin{array}{c}* \text { DPPH scavenging } \\
\text { activity [\%] }\end{array}$ & $* * A A[\%]$ & $I C_{50}[\mathrm{mg}]$ \\
\hline $\begin{array}{c}\text { Methanol } \\
\text { extract }\end{array}$ & $69.31 \pm 1.24^{a}$ & $47.98 \pm 0.94^{d}$ & $0.300 \pm 0.010^{b}$ \\
BHT & $89.16 \pm 1.83^{b}$ & $78.78 \pm 1.59^{d}$ & $0.020 \pm 0.001^{c}$ \\
BHA & $80.01 \pm 1.78^{a}$ & $79.15 \pm 0.24^{c}$ & $0.035 \pm 0.007^{c}$ \\
\hline
\end{tabular}

Data expressed as means \pm standard deviation $(n=3)$. Means within each column with different letters $(\mathrm{a}-\mathrm{c})$ differ significantly $(p<0.05)$.

*DPPH scavering activity [\%] at concentration of $0.5 \mathrm{mg}$ dry weight $\mathrm{ml}^{-1}$.

**Antioxidant activity by $\beta$-caroten system [\%] at concentration of $2 \mathrm{mg}$ dry weight $\mathrm{ml}^{-1}$.

\subsubsection{Inhibition of linoleic acid oxidation}

Antioxidants inhibit the volatile organic compounds and the conjugated diene hydroperoxides arised from linoleic acid oxidation. Therefore, they protect cells from oxidation of lipid components in cell membranes $[2,7]$.

In the $\beta$-carotene-linoleate bleaching assay, it was found that antioxidant compounds in the methanolic extract of Lavandula stoechas minimized the oxidation of $\beta$-carotene. Hydroperoxides formed by linoleic acid were neutralized by the antioxidants in the extract. Antioxidant activity of the extract was measured according to degradation rate of $\beta$-carotene. In the literature, it was determined that the extract with the lowest degradation rate of $\beta$-carotene exhibited the highest antioxidant activity $(A A)[15]$. In the present study, $A A$ of the extracts and standards was measured by degradation rate $(D R)$ of $\beta$-carotene. The results are given in Table I. The highest inhibition was provided by BHT and BHA (78.78 $\pm 1.59 \%$ and $79.15 \pm 0.24 \%$ ), followed by the extract of Lavandula stoechas $(47.98 \pm 0.94 \%)$ at concentration of $2 \mathrm{mg} / \mathrm{ml}$, as shown in Fig. 2.

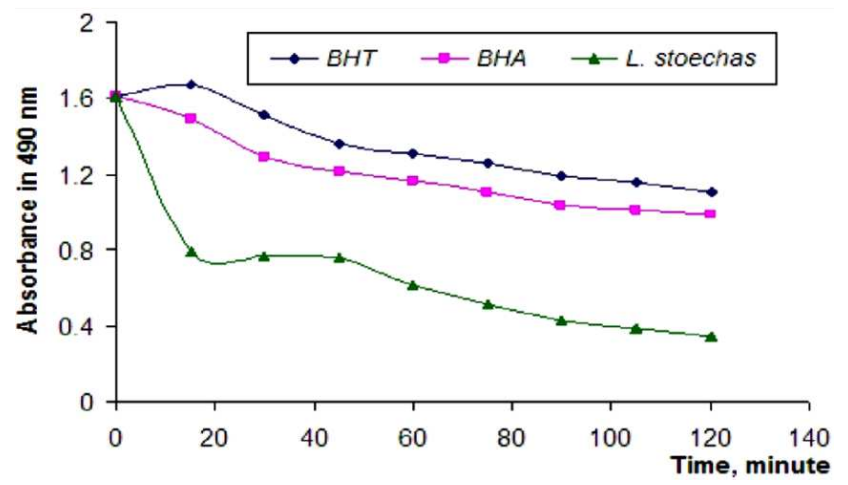

Fig. 2. Absorbance change of $\beta$-carotene at $490 \mathrm{~nm}$ in the presence of the methanolic extract of Lavandula stoechas, control and positive control BHT and BHA.

Considering the obtained results, it can be said that the methanolic extract of Lavandula stoechas has weaker 
activity than the standards, BHA and BHT. However, the high concentration of polar phenolics in the extract may promote the inhibition effect on linoleic acid oxidation.

\subsubsection{Ferric reducing antioxidant power (FRAP)}

Ferric reducing antioxidant power (FRAP) of an antioxidant was determined using FRAP assay. According to the absorbance values shown in Fig. 1b, FRAP of the extract on ferrous ions has exhibited a lower antioxidant potential than those of standards BHT and BHA. Higher absorbance means a higher ferric reducing antioxidant power. The reduction of antioxidant power of the plant extract on ferric ions is associated with their phytoconstituents such as phenolic acids and flavonoids, which exert breaking of the free radical chain. Thus, the redox potential of phenolic compounds has played an important role in determination of the antioxidant capacity [16, 17].

\subsubsection{Total phenolic content}

The plant extracts have significantly inhibited oxidating process although they are often oxidized themselves. This inhibition effect is attributed to phenolic compounds in the plants $[16,18]$. Total phenolic contents of the plant extracts imply antioxidant power of the extract. Therefore, the total phenolic content of the methanolic extract of Lavandula stoechas was measured and found to be $105.5 \pm 2.7 \mathrm{mg}$ gallic acid equivalents (GAE) per gramm of dry extract $(p<0.05)$.

\subsection{5. $H P L C$ analysis}

High antioxidant power is attributed to high amount of total phenolic content. However, in literature more than 6500 phenolic structures were identified by analytical tools, such as high performance liquid and gas chromatographic techniques. It is impossible to characterize all these structures at the same time. For this purpose, several typical phenolics, such as phenolic acids and flavonoids have been characterized in this study. Phenolic acids such as caffeic acid, ferulic acid and vanilic acid are widely present in the plants [8]. Selected phenolic compounds from the methanolic extract of Lavandula stoechas were also analyzed via comparison with authentic standards (Fig. 3). These are the gallic acid, catechin, caffeic acid, epicatechin, p-coumaric acid, ferulic acid, vitexin, rutin, naringin, hesperidin, apigenin, rosmarinic acid, eriodictyol, quercetin, naringenin, luteolin, apigenin and carvacrol. Considering the HPLC analysis in which $8.347 \mathrm{mg} \mathrm{g}^{-1}$ of rosmarinic acid, $0.875 \mathrm{mg} \mathrm{g}^{-1}$ of caffeic acid, $1.019 \mathrm{mg} \mathrm{g}^{-1}$ of quercetin, and $0.472 \mathrm{mg} \mathrm{g}^{-1}$ of rutin were used, it was found that phenolic acids in the extract was predominant over flavonoids (Table II).

According to the results of this study, it was determined that compounds isolated from Lavandula stoechas such as rutin, caffeic acid and rosmarinic acid may partly be responsible for the antioxidant activity of the total extract and may play important role in therapeutic efficiency of Lavandula stoechas [15].

\section{TABLE II}

Contents of several phenolic compounds in the methanolic extract of Lavandula stoechas.

\begin{tabular}{c|c}
\hline \hline Compounds & Amount $\left[\mathrm{mg} \mathrm{g}^{-1}\right]$ \\
\hline Gallic acid & - \\
Catechin hydrate & - \\
Caffeic acid & $0.875 \pm 0.024$ \\
Epicatechin & - \\
p-coumaric acid & $0.018 \pm 0.008$ \\
Ferulic acid & $0.033 \pm 0.006$ \\
Vitexin & - \\
Rutin & $0.472 \pm 0.093$ \\
Naringin & - \\
Hesperidin & - \\
Rosmarinic acid & $8.347 \pm 1.005$ \\
Eriodictyol & $0.055 \pm 0.010$ \\
Quercetin & $1.019 \pm 0.059$ \\
Naringenin & - \\
Carvacrol & - \\
\hline Data expressed $(P<0.05)$ as mean \\
\pm standard deviation $(n=3)$.
\end{tabular}

\subsection{ESR measurements}

ESR measurements have recently been carried out on antioxidants [19-21]. Antioxidant plants consist of many flavonoid compounds such as quercetin, vitexin, rutin and pyrogallol (myricetin). Quercetin is one of the flavonoids in the plants. Therefore, many researches have studied the antioxidant activity of quercetin [22, 23]. Miura, et al. observed one ESR line from the quercetin quenched with HRP, but they did not observe any ESR line from quercetin without quenching it with HRP [22]. In this study, ESR spectra were recorded from the methanolic extract of the Lavandula stoechas. The quercetin ESR spectrum without quenching, at the room temperature conditions is shown in Fig. 3.

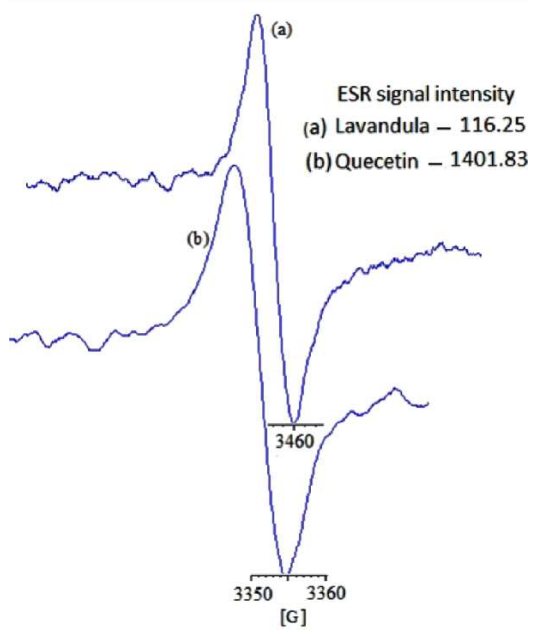

Fig. 3. ESR spectrum of the methanolic extract of $L a-$ vandula stoechas (a) and of quercetin (b) at $298 \mathrm{~K}$. 
The $g$-factor and free radical concentration were calculated for both the plant extract and the quercetin from the recorded the spectra. Results are shown in Table III.

TABLE III

$g$-values and radical concentrations for Lavandula stoechas and quercetin.

\begin{tabular}{c|c|c}
\hline \hline Materials & *Intensity of peaks & $g$-factor \\
\hline Lavandula stoechas & 116.25 & 2.0034 \\
Quercetin & $1.4 \times 10^{3}$ & 2.0052 \\
\hline
\end{tabular}

Dry weight of the samples is $0.5 \mathrm{mg}$

Temperature is $298 \mathrm{~K}$

*Intensity of ESR line is related with free radical con-

centration in this sample

These results show that the free radical concentration in the quercetin is more than that in the extract and also magnetic environment of free electron in the quercetin is different from that in the plant extract.

\section{Conclusions}

Lavandula stoechas might be a new potential natural antioxidant source due to having high antioxidant activity. The methanolic extract of Lavandula stoechas is a complex mixture of phenolic acids and flavonoid compounds. Therefore, it is important to analyse phenolic compounds which are contributing to the antioxidant activity. In this study, it was the first time we have investigated relationship between radical scavenging effect and ESR signals of Lavandula stoechas extract. ESR results showed that the free radical scavenging effect of Lavandula stoechas is stronger than that of quercetin, because the intensity of ESR line of the plant extract is smaller than that of the quercetin.

\section{Acknowledgments}

We thank Scientific Research Foundations of Selcuk and Alanya Alaaddin Keykubat Universities for supporting this study.

\section{References}

[1] A.M. Minino, B.L. Smith, National Vital Statistics Reports 49, 1 (2001).

[2] N. Kartal, M. Sokmen, B. Tepe, D. Daferera, M. Polissiou, A. Sokmen, Food Chem. 100, 584 (2007).
[3] N. Gámez-Meza, J.A. Noriega-Rodríguez, L.A. Medina-Juárez, J. Ortega-García, R. Cázarez-Casanova, A. Guerrero, J. Am. Oil Chem. Soc. 76, 1445 (1999).

[4] S. Buxiang, M. Fukuhara, Toxicology 12, 61 (1997).

[5] K.L. Fritz, C.M. Seppanen, M.S. Kurzer, A.S. Csallany, Nutr. Res. 23, 479 (2003).

[6] J.D. Philipson, Plants as sources of valuable products, in Secondary products from plant tissue culture, Eds. B.V. Charlwood, M.J. Rhodes, Clarendon Press, Oxford 1990, p. 1.

[7] Y.S. Velioglu, G. Mazza, L. Gao, B.D. Oomah, J. Agr. Food Chem. 46, 4113 (1998).

[8] M.S. Al-Saikhan, L.R. Howard, J.C. Miller, J. Food Sci. 60, 341 (1995).

[9] C. Sanchez-Moreno, J.A. Larrauri, F.A. SauraCalixto, J. Sci. Food Agric. 76, 270 (1998).

[10] M. Oyaizu, Jpn J. Nutr. 44, 307 (1986).

[11] V.L. Singleton, J.A. Rossi, Am. J. Enol. Vitic. 16 144 (1965).

[12] E. Maltas, S. Yildiz, J. Food Biochem. 35, 1071 (2011).

[13] V. Katalinic, M. Milos, D. Modun, I. Musc, M. Boban, Food Chem. 86, 593 (2004).

[14] R. Apak, K. Güçlü, M. Özyürek, S.E. Karademir, J. Agric. Food Chem. 52, 7970 (2004).

[15] A. Othman, A. Ismail, N.A. Ghani, I. Adenan, Food Chem. 100, 1523 (2007).

[16] I. Urquiaga, F. Leighton, Biol. Res. 33, 55 (2000).

[17] C.A. Rice-Evans, N.J. Miller, G. Paganga, Trends in Plant Sci. 2, 152 (1997).

[18] Y.Y. Soong, P.J. Barlow, Food Chem. 88, 411 (2004).

[19] M. Antolovich, P.D. Prenzier, E. Patsalides, S. McDonald, K. Robards, Analyst. 127, 183 (2002).

[20] P.S. Hegde, T.S. Chandra, Food Chem. 92, 177 (2005).

[21] T. Miura, S. Muraoka, Y. Fujimoto, Food Chem. Toxicol. 41, 759 (2003).

[22] M. Polovka, V. Brezova, A. Stasko, Biophys. Chem. 106), 39 (2003).

[23] C. Jullian, L. Moyano, C. Yanez, C. Olea-Azar, Spectrochim. Acta, Part A, Mol. Biomol. Spectrosc. 67, 230 (2007). 